\title{
Perilesional edema associated with an intracranial calcifying pseudoneoplasm of the neuraxis in a child: case report and review of imaging features
}

\author{
Michael M. Safaee, MD, ${ }^{1}$ Soren Jonzzon, BS, ${ }^{1}$ Giselle Y. López, MD, PhD, ${ }^{2}$ Shailesh Asaikar, MD, ${ }^{3}$ \\ Tarik Tihan, MD, PhD, ${ }^{2}$ Orit A. Glenn, MD, ${ }^{4}$ and Nalin Gupta, MD, PhD',5 \\ 'Department of Neurological Surgery, University of California, San Francisco; ${ }^{2}$ Department of Pathology, Division of \\ Neuropathology, University of California, San Francisco; ${ }^{3} \mathrm{Child}$ and Adolescent Neurology Associates, Sacramento; ${ }^{4}$ Department \\ of Radiology, Division of Neuroradiology, University of California, San Francisco; and ${ }^{5}$ Department of Pediatrics, University of \\ California, San Francisco, California
}

\begin{abstract}
Calcifying pseudoneoplasms of the neuraxis (CAPNONs) are rare, nonneoplastic lesions of the CNS. Their radiographic features have been well described, with prominent calcifications seen on CT imaging and generally uniform hypointensity on T1- and T2-weighted MRI sequences, with variable patterns of contrast enhancement. They are not associated with significant perilesional edema. The authors present an unusual case of an 8-year-old boy who was found to have a 2.5$\mathrm{cm}$ right frontal mass that demonstrated reduced signal on T2-weighted sequences, heterogeneous contrast enhancement, and extensive perilesional edema on MRI sequences. The differential diagnoses included a chronic infection or neoplasm. He underwent gross-total resection of a firm, calcified mass that had clear boundaries between it and the surrounding gliotic brain. Pathological analysis demonstrated a well-circumscribed lesion with islands of lamellar calcifications and intervening spindle cells, consistent with a CAPNON. At 8 months after surgery the patient remained seizure free, and MRI revealed no evidence of residual lesion and significant improvement in perilesional edema. This particular case highlights the potential for unusual presentation of CAPNON and the rare presence of perilesional edema.

https://thejns.org/doi/abs/10.3171/2018.5.PEDS18104
\end{abstract}

KEYWORDS CAPNON; calcifying pseudoneoplasm of the neuraxis; pediatric; brain tumor; oncology

$\mathrm{C}$ ALCIFYING pseudoneoplasms of the neuraxis (CAPNONs) are rare, nonneoplastic lesions of the CNS first described by Rhodes and Davis in 1978.11 They occur with similar frequency in the brain and spine and can be either intra- or extraaxial. ${ }^{1}$ The etiology and cell of origin of these lesions are unclear, but their pathogenesis is believed to be reactive, not neoplastic. ${ }^{5}$ The clinical presentation is generally associated with headaches, seizures, or focal motor or sensory deficits related to mass effect. Classic histopathological findings are variable but generally include certain common elements: 1) a chondromyxoid matrix in a nodular pattern; 2) palisading spindle to epithelioid cells; 3 ) variable fibrous stroma; 4) calcification, osseous metaplasia, and scattered psammoma bodies; and 5) foreign-body reaction with giant cells-however, the presence of each component is variable. ${ }^{7,10}$ In general, CAPNONs feature a lobulated-appearing, reactive process and basophilic amorphous to fibrillary material that are sometimes described as "chicken-feet calcifications." ${ }^{8,9}$ It is thought that these lesions might develop as a healing response to an inciting factor such as trauma, infection, or inflammation, but this has not been definitely proven. Gross-total resection of these lesions is usually curative and outcomes are generally excellent.

The radiographic features of CAPNONs have been well described. These lesions are heavily calcified on CT imaging and are generally uniformly hypointense on T1- and T2-weighted MRI sequences with variable patterns of contrast enhancement, generally in the form of a minimal linear rim or serpiginous internal enhancement, with

ABBREVIATIONS CAPNON = calcifying pseudoneoplasm of the neuraxis; GFAP = glial fibrillary acidic protein.

SUBMITTED February 14, 2018. ACCEPTED May 23, 2018.

INCLUDE WHEN CITING Published online August 17, 2018; DOI: 10.3171/2018.5.PEDS18104. 

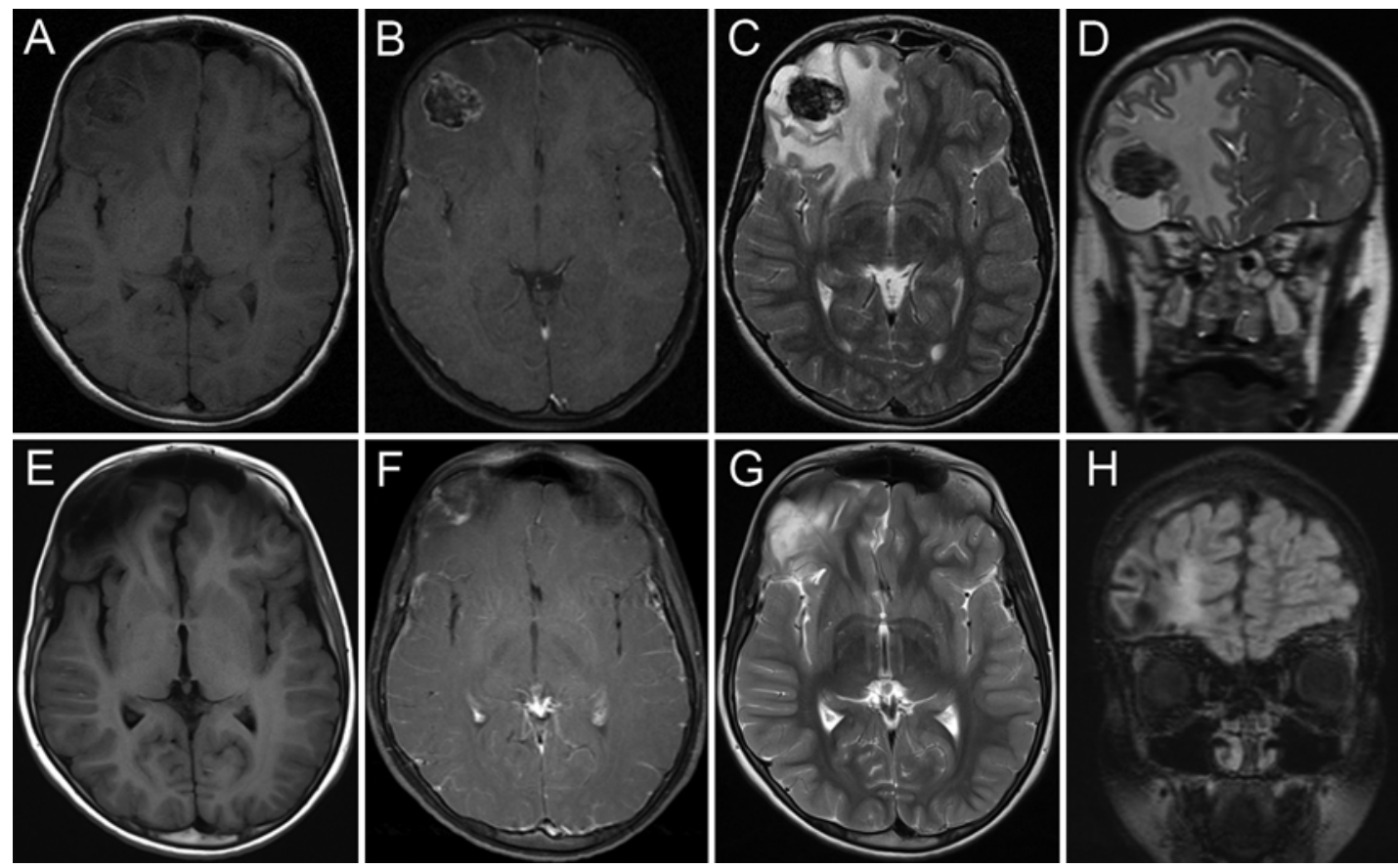

FIG. 1. Preoperative and postoperative MRI of intracranial CAPNON. Preoperative T1-weighted MRI revealed a $2.5-\mathrm{cm}$ hypointense nodule in the right frontal lobe $(\mathbf{A})$ with heterogeneous contrast enhancement mostly centered at the periphery (B). T2-weighted MRI showed a hypointense lesion with significant perilesional edema (C). There was an associated cyst inferior to the nodule, with thinning of the overlying frontal bone and expansion of the hemicranium (D). Postoperative MRI performed 8 months after resection revealed no evidence of residual or recurrent tumor on T1-weighted MRI (E) and no residual abnormal contrast enhancement (F). T2-weighted MRI showed dramatic improvement in the associated perilesional edema (G), with no residual cyst on FLAIR MRI $(\mathbf{H})$.

limited to no surrounding edema. ${ }^{1}$ Important differential diagnoses for intraaxial lesions with these characteristics include ganglioglioma, oligodendroglioma, cavernous malformations, and tuberculosis. Calcified lesions with heterogeneous hyperintensity on T2-weighted imaging are more likely to be neoplasms, whereas those with a typical "popcorn" hyperintensity on T2-weighted imaging and hemosiderin ring are more likely to be cavernous malformations.

We present a case of an intracranial intraaxial CAPNON that is unique because of the patient's age and the lesion's radiographic features. The MRI findings in our case demonstrated marked perilesional edema that has only rarely been described..$^{12}$ This case highlights the diverse appearance of CAPNONs and the need to maintain a broad differential when evaluating these lesions.

\section{Case Report}

History and Examination

An 8-year-old boy with no significant medical history was referred to our institution with remote episodes consisting of alterations in consciousness, consistent with seizures. An MRI sequence demonstrated a $2.5-\mathrm{cm}$ T2 hypointense right frontal lesion with heterogeneous contrast enhancement and extensive perilesional edema (Fig. $1 \mathrm{~A}-\mathrm{C})$. There was also a cystic lesion inferior to the nodule with associated mass effect on the frontal lobe, with expansion of the hemicranium and thinning of the overlying bone (Fig. 1D). The patient was a recent immigrant from Afghanistan but did not have a history of a systemic illness. Specifically, weight loss, fever, and malaise were not present. The initial differential diagnosis included a chronic infectious process or, less likely, a neoplasm. Serum inflammatory markers were in a normal range, and results of a tuberculosis skin test were negative.

\section{Operation}

After a discussion of the potential diagnoses with the patient's parents, a right frontal craniotomy was performed. The cortex overlying the mass was pale and cystic. The underlying lesion was very firm, with a clear boundary between the mass and the surrounding gliotic brain. A surgical plane was easily identified. There were numerous small vessels extending from the brain toward the mass that were divided without difficulty. Along the inferior border, the mass abutted an associated cyst, which was fenestrated and drained of clear and colorless fluid. Based on the intraoperative impression, no residual component of the mass was noted. The cortex medial and anterior to the lesion appeared abnormal and partially cystic; this was removed and sent for additional analysis. An immediate postoperative MRI sequence showed an apparent grosstotal resection. The patient had an unremarkable hospital stay and was discharged with no new neurological deficits. 


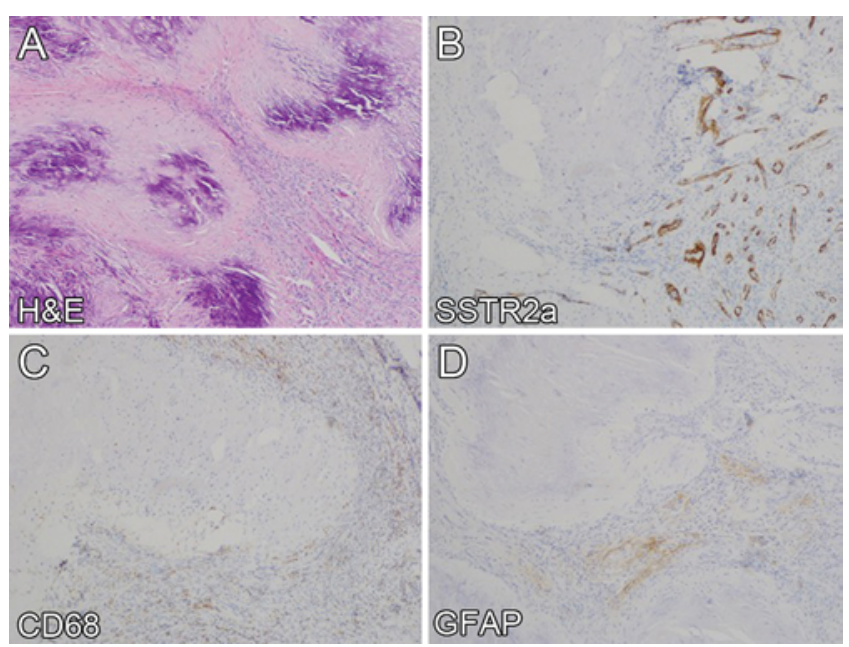

FIG. 2. Photomicrographs showing pathological features of CAPNON. A: The H \& E-stained specimen features islands of lamellar calcifications with intervening spindle cells. B: Immunostaining of spindle cells was negative for SSTR2a, a marker of meningeal cells. C: CD68, a marker of macrophages, showed scattered positivity, but was negative in the spindle cell population. D: GFAP staining was negative, highlighting the sharp demarcation between the lesion and surrounding brain parenchyma. The final diagnosis was CAPNON. Original magnification $\times 10$. Figure is available in color online only.

\section{Histopathological Findings}

On histopathological analysis, the specimen was a well-circumscribed lesion composed of islands of lamellar calcifications with intervening spindle cells (Fig. 2A). There were no mitoses or necrosis identified. Immunohistochemical staining was used to characterize the spindle cells, which were negative for SSTR2a, a marker of meningeal cells (Fig. 2B). CD68 staining highlighted scattered macrophages, but was negative in the spindle cell population (Fig. 2C). Glial fibrillary acidic protein (GFAP) showed a faint blush but was otherwise negative, highlighting the sharp demarcation between the lesion and surrounding parenchyma (Fig. 2D). The final diagnosis was confirmed as CAPNON.

\section{Postoperative Course}

A follow-up MRI sequence obtained 8 months after surgery showed no evidence of a residual lesion and significant improvement in perilesional edema (Fig. 1E-H). There was some evidence of volume loss, suggesting that the edema was long-standing. The patient remains neurologically intact and was weaned from his anticonvulsants with no further seizures.

\section{Discussion}

CAPNONs are rare lesions, with fewer than 70 cases reported in the literature; only 4 of these occurred in children (age $<18$ years). Bertoni et al. reported on a 12-year-old boy with an extradural spinal lesion at C6 causing neck pain; ${ }^{4}$ Tatke et al. reported on a 6-year-old boy with an intraaxial temporal lobe lesion causing seizures, ${ }^{13}$ Aiken et al. reported on a 16-year-old girl with an incidental temporal lobe lesion; ${ }^{1}$ and Bartanusz et al. reported on a 22-month-old girl with an extradural lesion at $\mathrm{C} 1-2 .^{3}$ These cases are summarized in Table 1. Because CT scans are used sparingly in pediatric patients unless there is trauma, the radiographic features of these lesions are generally limited to MRI sequences. However, it is unlikely that the CT findings would have changed the management in any of these cases.

The preferred treatment for symptomatic CAPNONs is resection. This is associated with excellent outcomes because there are only 2 reported cases of recurrence despite several cases of incomplete resection in adult and pediatric patients. ${ }^{2,4,6}$ All of the pediatric patients presented in the literature had good outcomes; however, it is unclear if this is due to the success of the intervention or the indolent nature of these lesions. Indeed, for asymptomatic tumors, the natural history of these lesions is not well defined.

The case presented in this paper is unique because of the presence of dramatic perilesional edema, which is not usually associated with a CAPNON. This lesion also had an associated cyst, with expansion and thinning of the overlying cranium. The differential diagnosis of calcified lesions of the brain and spine is broad and can include meningioma, chordoma, chondrosarcoma, schwannoma,

TABLE 1. Literature review of CAPNON in pediatric patients

\begin{tabular}{|c|c|c|c|c|c|c|}
\hline $\begin{array}{l}\text { Authors \& } \\
\quad \text { Year }\end{array}$ & Age, Sex & $\begin{array}{l}\text { Lesion } \\
\text { Location }\end{array}$ & $\begin{array}{l}\text { Presenting } \\
\quad \text { Sx }\end{array}$ & Imaging Features & Treatment & Outcome \\
\hline $\begin{array}{l}\text { Bertoni et al., } \\
\quad 1990\end{array}$ & 12 yrs, M & $\begin{array}{l}\text { Spine C6 } \\
\text { (E) }\end{array}$ & Neck pain & NA & $\begin{array}{l}\text { Partial } \\
\text { resection }\end{array}$ & Progression free \\
\hline $\begin{array}{l}\text { Tatke et al., } \\
2001\end{array}$ & 6 yrs, M & $\begin{array}{r}\text { Temporal } \\
\text { lobe }(I)\end{array}$ & Seizures & NA & $\begin{array}{l}\text { Partial } \\
\text { resection }\end{array}$ & Progression free \\
\hline $\begin{array}{l}\text { Aiken et al., } \\
2009\end{array}$ & $16 \mathrm{yrs}, \mathrm{F}$ & $\begin{array}{l}\text { Temporal } \\
\text { horn }(I)\end{array}$ & Incidental & $\begin{array}{l}\text { T1 \& T2 hypo, internal linear contrast } \\
\text { enhancement }\end{array}$ & $\begin{array}{l}\text { Complete } \\
\text { resection }\end{array}$ & NA \\
\hline $\begin{array}{l}\text { Bartanusz et } \\
\text { al., } 2013\end{array}$ & 22 mos, $F$ & $\begin{array}{l}\text { Spine } C 1-2 \\
(E)\end{array}$ & $\begin{array}{l}\text { Torticollis \& } \\
\text { neck pain }\end{array}$ & $\begin{array}{l}\text { Calcified on CT, T1 \& T2 hypo, trace periph- } \\
\text { eral contrast enhancement }\end{array}$ & Open biopsy & $\begin{array}{l}\text { Complete resolution of torticollis } \\
\text { \& neck pain }\end{array}$ \\
\hline Present case & 8 yrs, M & $\begin{array}{l}\text { Frontal } \\
\quad \text { lobe }(I)\end{array}$ & Seizures & $\begin{array}{l}\text { T1 \& T2 hypo, heterogeneous peripheral en- } \\
\text { hancement, significant perilesional edema }\end{array}$ & $\begin{array}{l}\text { Complete } \\
\text { resection }\end{array}$ & $\begin{array}{l}\text { Asymptomatic w/ no evidence of } \\
\text { recurrent disease }\end{array}$ \\
\hline
\end{tabular}

$\mathrm{E}=$ extraaxial; hypo = hypointense $; \mathrm{I}=$ intraaxial; $\mathrm{NA}=$ not available; $\mathrm{Sx}=$ symptoms . 
ganglioglioma, oligodendroglioma, cavernous malformations, tuberculosis, choroid plexus tumors, or ependymal tumors. Certain imaging features can help narrow the diagnosis; for example, calcified meningiomas can be distinguished by their dural tail and chordomas/chondrosarcomas generally feature hyperintensity on T2-weighted images, contrast enhancement, and a more aggressive invasion of adjacent soft tissues.

It is unclear why this particular case was associated with such significant perilesional edema. There were no pathological features that deviated from classic CAPNON and no evidence of increased inflammation that would explain the radiographic findings. Although the patient's seizures had occurred well before the imaging studies obtained in this case, one possibility is that the surrounding brain was edematous from those previous or potentially ongoing subclinical seizures. Furthermore, the expansion and thinning of the overlying cranium suggest a chronic process, which in a small child may contribute to the development of brain edema. Finally, the etiology of the cystic lesion is not clear. Although it may have been an incidental arachnoid cyst, the more likely possibility is that it was secondary to the formation of the CAPNON. This particular case highlights the potential for unusual presentation of CAPNONs and the rare presence of significant perilesional edema.

\section{Conclusions}

CAPNON remains a diagnostic dilemma given its rarity and broad differential of similar featured lesions. Although intraaxial lesions are rarely associated with cerebral edema, we present a unique case of a pediatric patient with dramatic perilesional edema associated with a frontal lobe CAPNON. This case illustrates the enigmatic behavior of these lesions and their excellent prognosis with safe resection.

\section{References}

1. Aiken AH, Akgun H, Tihan T, Barbaro N, Glastonbury C: Calcifying pseudoneoplasms of the neuraxis: CT, MR imaging, and histologic features. AJNR Am J Neuroradiol 30:1256-1260, 2009

2. Alshareef M, Vargas J, Welsh CT, Kalhorn SP: Calcifying pseudoneoplasm of the cervicomedullary junction: case report and a literature review. World Neurosurg 85:364. e11-364.e18, 2016
3. Bartanusz V, Ziu M, Jimenez DF, Henry JM: Calcifying pseudoneoplasm of the atlantoaxial joint in a child. J Neurosurg Spine 18:367-371, 2013

4. Bertoni F, Unni KK, Dahlin DC, Beabout JW, Onofrio BM: Calcifying pseudoneoplasms of the neural axis. J Neurosurg 72:42-48, 1990

5. Brasiliense LB, Dickson DW, Nakhleh RE, Tawk RG, Wharen R: Multiple calcifying pseudoneoplasms of the neuraxis. Cureus 9:e1044, 2017

6. Chang H, Park JB, Kim KW: Intraosseous calcifying pseudotumor of the axis: a case report. Spine (Phila Pa 1976) 25:1036-1039, 2000

7. García Duque S, Medina Lopez D, Ortiz de Méndivil A, Diamantopoulos Fernández J: Calcifying pseudoneoplasms of the neuraxis: report on four cases and review of the literature. Clin Neurol Neurosurg 143:116-120, 2016

8. Kleinschmidt-DeMasters BK, Rodriguez F, Tihan T: Diagnostic Pathology: Neuropathology. Philadelphia: Elsevier, 2016

9. Perry A, Brat D: Practical Surgical Neuropathology: A Diagnostic Approach. Philadelphia: Elsevier, 2017

10. Qian J, Rubio A, Powers JM, Rosenblum MK, Pilcher WH, Shrier DA, et al: Fibro-osseous lesions of the central nervous system: report of four cases and literature review. Am J Surg Pathol 23:1270-1275, 1999

11. Rhodes RH, Davis RL: An unusual fibro-osseous component in intracranial lesions. Hum Pathol 9:309-319, 1978

12. Shrier DA, Melville D, Millet D, Qian J, Millet D, Nelson C, et al: Fibro-osseous lesions involving the brain: MRI. Neuroradiology 41:18-21, 1999

13. Tatke M, Singh AK, Gupta V: Calcifying pseudoneoplasm of the CNS. Br J Neurosurg 15:521-523, 2001

\section{Disclosures}

The authors report no conflict of interest concerning the materials or methods used in this study or the findings specified in this paper.

\section{Author Contributions}

Conception and design: Gupta. Acquisition of data: Safaee, Jonzzon, López. Analysis and interpretation of data: Gupta, Safaee, López, Tihan, Glenn. Drafting the article: Gupta, Safaee, Jonzzon. Critically revising the article: Gupta, Safaee, López, Tihan, Glenn. Reviewed submitted version of manuscript: Gupta, Safaee, Asaikar, Tihan, Glenn. Administrative/technical/material support: Gupta. Study supervision: Gupta.

\section{Correspondence}

Nalin Gupta: UCSF Benioff Children's Hospital, San Francisco, CA.nalin.gupta@ucsf.edu. 